\title{
A novel nested multiplex polymerase chain reaction (PCR) assay for differential detection of Entamoeba histolytica, E. moshkovskii and $E$. dispar DNA in stool samples Krishna Khairnar and Subhash C Parija*
}

\author{
Address: Department of Microbiology, Jawaharlal Institute of Postgraduate Medical Education and Research (JIPMER), Puducherry, India \\ Email: Krishna Khairnar - kskhairnar@yahoo.co.in; Subhash C Parija* - parijasc@vsnl.com \\ * Corresponding author
}

Published: 24 May 2007

BMC Microbiology 2007, 7:47 doi:10.1 186/147/-2180-7-47

This article is available from: http://www.biomedcentral.com/I47/-2/80/7/47

(c) 2007 Khairnar and Parija; licensee BioMed Central Ltd.

This is an Open Access article distributed under the terms of the Creative Commons Attribution License (http://creativecommons.org/licenses/by/2.0), which permits unrestricted use, distribution, and reproduction in any medium, provided the original work is properly cited.

\begin{abstract}
Background: E. histolytica, a pathogenic amoeba, is indistinguishable in its cyst and trophozoite stages from those of non-pathogenic $E$. moshkovskii and $E$. dispar by light microscopy. We have developed a nested multiplex PCR targeting a I6S-like rRNA gene for differential detection of all the three morphologically similar forms of E. histolytica, E. moshkovskii and E. dispar simultaneously in stool samples.
\end{abstract}

Results: The species specific product size for E. histolytica, E. moshkovskii and E. dispar was 439, 553 and 174 bp respectively, which was clearly different for all the three Entamoeba species. The nested multiplex PCR showed a sensitivity of $94 \%$ and specificity of $100 \%$ for the demonstration of $E$. histolytica, E. moshkovskii and E. dispar DNA in stool samples. The PCR was positive for $E$. histolytica, E. moshkovskii and E. dispar in a total of 190 out of 202 stool specimens ( $94 \%$ sensitive) that were positive for E. histolyticalE. dispar/E. moshkovskii by examination of stool by microscopy and/or culture. All the 35 negative control stool samples that were negative for $E$. histolytica/E. dispar/E. moshkovskii by microscopy and culture were also found negative by the nested multiplex PCR (I00\% specific). The result from the study shows that only $34.6 \%$ of the patient stool samples that were positive for $E$. histolytica/E. dispar/E. moshkovskii by examination of stool by microscopy and/or culture, were actually positive for pathogenic $E$. histolytica and the remaining majority of the stool samples were positive for non-pathogenic E. dispar or E. moshkovskii as demonstrated by the use of nested multiplex PCR.

Conclusion: The present study reports a new nested multiplex PCR strategy for species specific detection and differentiation of $E$. histolytica, $E$. dispar and $E$. moshkovskii DNA in stool specimens. The test is highly specific, sensitive and also rapid, providing the results within 12 hours of receiving stool specimens.

\section{Background}

Infection with Entamoeba histolytica results in 34 million to 50 million symptomatic cases of amoebiasis worldwide each year, causing 40 thousand to 100 thousand deaths annually [1]. E. histolytica, the pathogenic amoeba, is indistinguishable in its cyst and trophozoite stages from those of non-pathogenic E. dispar [1] and E. moshkouskii [2], except in rare cases of invasive disease when E. histo- 
lytica trophozoite may contain ingested red blood cells [3]. Estimates of intestinal E. histolytica infections have been primarily based on microscopic examination of stools, which has a sensitivity of only $60 \%$, even under optimal standards $[4,5]$. The microscopic examination of stool alone, however, fails to differentiate E. histolytica from those of morphologically similar non-pathogenic species such as E. dispar and E. moshkovskii. Stool culture followed by isoenzyme analysis enables the differentiation of E. histolytica from E. dispar [6]. However, this method of culture when followed by isoenzyme analysis requires one to several weeks to obtain the result and also special laboratory facilities, making it impractical for use in the routine diagnosis of intestinal amoebiasis.

Various approaches are being followed for specific identification and detection of E. histolytica in stool specimens such as detection of E. histolytica coproantigen in stool samples by enzyme-linked immuno-sorbent assay (ELISA) and detection of E. histolytica DNA in stool samples by polymerase chain reaction (PCR). Currently few commercial ELISA kits are available for detection of E. histolytica/E. dispar coproantigen in stool. These include TechLab Entamoeba test to detect E. histolytica/E. dispar [5], Alexon ProSpecT ELISA to detect E. histolytica/E. dispar and Giardia lamblia [7] and Triage parasite panel to detect antigen of E. histolytica/E. dispar, Giardia lamblia and Cryptosporidium parvum in stool specimens [8]. The main limitation of all these ELISA kits is that they can identify the amoebae only as E. histolytica-E. dispar complex but not specifically as E. histolytica, E. dispar or E. moshkovskii. However, a monoclonal antibody based Tech Lab E. histolytica II ELISA is commercially available for the specific detection of E. histolytica antigen directly in stool specimen [9], but this kit can neither detect E. dispar nor E. moshkovskii in stool specimen.
Recently, a nested PCR targeting 16S-like rRNA gene has been reported from the International Centre for Diarrhoeal Disease Research, Dhaka, Bangladesh (ICDDR,B) [2] as well as from our laboratory at Jawaharlal Institute of Postgraduate Medical Education and Research (JIPMER) hospital, Puducherry, India [10] to detect and differentiate E. histolytica, E. dispar and E. moshkovskii directly in stool specimens. But the identification of the amoeba in the stool specimens either as E. histolytica, E. dispar or E. moshkovskii was carried out by performing nested PCR each time separately for individual species which was tedious. To overcome this disadvantage, the main objective of the present study was to develop and evaluate a nested multiplex PCR targeting the 16S- like rRNA gene for simultaneous detection and differentiation of E. histolytica, E. moshkovskii and E. dispar directly in stool samples.

\section{Results}

\section{Microscopy and culture of stool}

A total of 202 out of 1,720 stool samples screened were positive for E. histolytica/E. dispar/E. moshkovskii by microscopy and/or culture. These included 164 specimens positive for E. histolytica/E. dispar/E. moshkovskii by both microscopy and culture, 22 positive by microscopy and 16 positive by culture (Table 1). All the 35 negative control stool samples were negative for $E$. histolytica/E. dispar/E. moshkovskii by microscopy and culture.

\section{Nested multiplex PCR}

Quantification of DNA in stool specimen

The DNA yield was found to be approximately $49 \mu \mathrm{g} / \mathrm{ml}$. The purity of DNA extract from stool specimen was found to be satisfactory as the value of ratio of readings at 260 $\mathrm{nm}$ and $280 \mathrm{~nm}\left(\mathrm{OD}_{260} / \mathrm{OD}_{280}\right.$ ) was approximately 1.8.

Table I: Comparison of results of nested multiplex PCR (Polymerase Chain Reaction), microscopy and culture on stool specimens.

\begin{tabular}{|c|c|c|c|c|c|}
\hline \multirow[t]{2}{*}{ Nested multiplex PCR result } & \multicolumn{4}{|c|}{ Microscopy and culture result $a$} & \multirow{2}{*}{$\begin{array}{l}\text { Total no. of } \\
\text { specimen }\end{array}$} \\
\hline & $\begin{array}{l}\text { Positive by microscopy } \\
\text { and culture }\end{array}$ & $\begin{array}{l}\text { Positive by } \\
\text { microscopy only }\end{array}$ & $\begin{array}{l}\text { Positive by } \\
\text { culture only }\end{array}$ & $\begin{array}{c}\text { Negative by microscopy } \\
\text { and culture }\end{array}$ & \\
\hline E. dispar (mono infection) & 80 & 16 & 4 & 0 & 100 \\
\hline E. histolytica (mono infection) & 12 & 2 & $\mathbf{I}$ & 0 & 15 \\
\hline E. moshkovskii (mono infection) & 2 & $\mathbf{0}$ & $\mathbf{0}$ & $\mathbf{0}$ & 2 \\
\hline E. dispar + E. moshkovskii (mixed) & 16 & $\mathbf{0}$ & 2 & $\mathbf{0}$ & 18 \\
\hline E. dispar + E. histolytica (mixed) & 35 & 2 & $\mathbf{I}$ & 0 & 38 \\
\hline E. histolytica + E.moshkovskii (mixed) & 2 & $\mathbf{0}$ & 0 & 0 & 2 \\
\hline E.dispar+E.histolytica+E.moshkovskii (mixed) & 15 & $\mathbf{0}$ & $\mathbf{0}$ & $\mathbf{0}$ & 15 \\
\hline Negative & 2 & 2 & 8 & 35 & 47 \\
\hline Total & 164 & 22 & 16 & 35 & 237 \\
\hline
\end{tabular}

${ }^{a}$ Microscopy and culture was unable to distinguish between cyst and trophozoite of E. histolytica, E. dispar and E. moshkovskii in stool specimens. 


\section{Primer validation}

The sequencing result of PCR product of E. dispar, E. histolytica and E. moshkovskii Laredo showed 99\% to $100 \%$ identity to the sequences of E. dispar, E. histolytica and E. moshkovskii Laredo, deposited in GenBank with accession number [GenBank:Z49256], [GenBank:X56991] and [GenBank: $\underline{A F 149906}]$ respectively.

\section{Assessment of competition for non-target DNA}

The assessment of competition of other non-target DNA present in stool DNA extract with a target DNA in nested multiplex PCR showed expected amplification without any non-specific amplification.

Estimation of minimum number of Entamoeba cells detectable by nested multiplex PCR

The nested multiplex PCR detected E. histolytica, E. dispar and E. moshkovskii DNA, even at the minimum parasite concentration tested (1000 parasites/0.05 grams of faeces). The detection limit of nested multiplex PCR for $E$. histolytica, E. dispar and E. moshkovskii was found to be approximately 25 Entamoeba protozoa cells, since $2.5 \mu \mathrm{l}$ of template DNA (1000 parasite/100 $\mu$ l of TE buffer) gave positive signal (Figure 1).

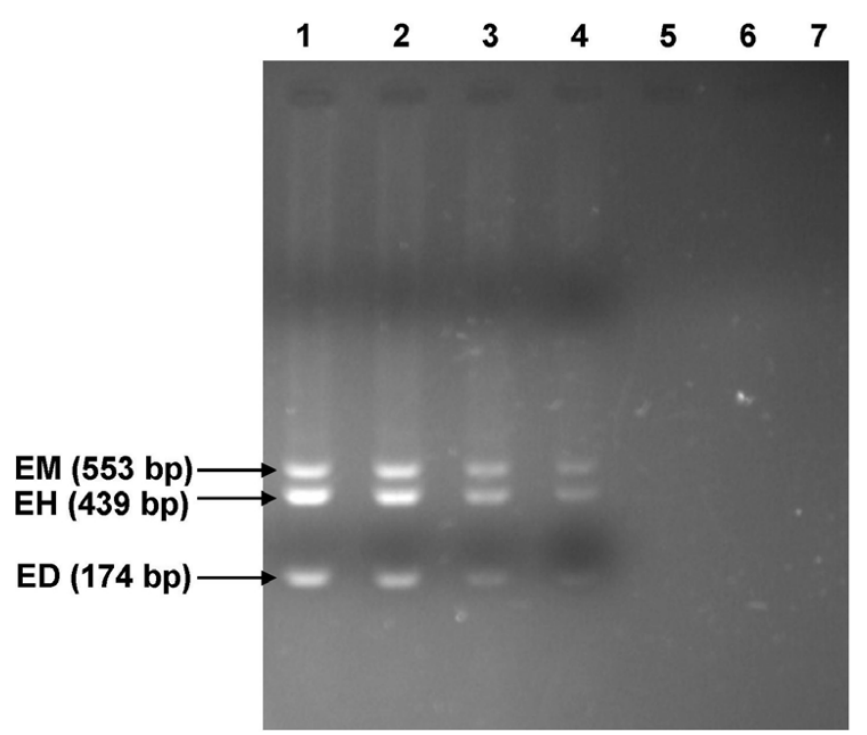

\section{Figure I}

Sensitivity of PCR for detection of minimum number of $E$. moshkovskii (EM), E. histolytica (EH) and E. dispar (ED) cells. $0.05 \mathrm{gm}$ of negative control stool specimen seeded with serially diluted Entamoeba cells corresponding to $10^{6}$ cells (lane I), $10^{5}$ cells (lane 2 ), $10^{4}$ cells (lane 3 ), $10^{3}$ cells (lane 4 ), $10^{2}$ cells (lane 5), and 10 cells (lane 6) were subjected to DNA extraction followed by PCR amplification. Amplified products were analyzed by agarose gel electrophoresis. The sizes of the amplification products are indicated on the left (in base pairs). Lanes 7, negative control (PCR without DNA)
Estimation of nested multiplex PCR to detect mixed infections with $\mathrm{E}$. histolytica, E. dispar and E. moshkovskii species

1000 cells of E. dispar and E. moshkovskii species as the background allowed for the detection of a 0.01 cell of $E$. histolytica; 1000 cells of E. histolytica and E. moshkovskii species as the background allowed for the detection of a 0.001 cell of E. dispar ; and 1000 cells of E. histolytica and E. dispar species as the background allowed for the detection of a 0.1 cell of E. moshkovskii (Figure 2).

\section{Cross checking the results of nested multiplex PCR}

The cross checking of the results of nested multiplex PCR was satisfactory as the same results were reproduced in randomly selected samples showing a mixed infection when subjected to individual species specific PCR in separate tubes.

\section{Nested multiplex PCR}

The nested multiplex PCR developed and evaluated in the present study showed that the size of diagnostic fragments of PCR products was clearly different for all the three Entamoeba species, the species-specific product size for E. histolytica, E. moshkovskii and E. dispar was 439, 553 and 174 bp respectively (Figure 3 ).

The nested multiplex PCR was performed on a total of 237 stool specimens including 202 stool specimens positive for E. histolytica, E. dispar, or E. moshkovskii by microscopy and/or culture, and 35 amoebae-negative control stool specimens. The nested multiplex PCR was positive in 190 out of 202 stool specimens that were positive for E. histolytica/E. dispar/E. moshkovskii complex trophozoites/cysts by microscopy and/or culture, thus showing a sensitivity of 94\%. All the 35 negative control stool samples were negative by nested multiplex PCR thus showing a specificity of $100 \%$.

The probability of negative nested multiplex PCR results in 35 control stool samples due to PCR inhibitors was ruled out by spiking the DNA of negative stool specimens with standard DNA of Entamoeba followed by nested multiplex PCR amplification.

The nested multiplex PCR detected mono-infection with E. histolytica in 7.4\% (15 of 202), E. dispar in 49.5\% (100 of 202) and E. moshkovskii in 1.0\% (2 of 202) of stool samples. The PCR also detected mixed infections by both E. dispar and E. moshkovskii in 8.9\% (18 of 202), E. dispar and E. histolytica in $18.8 \%$ (38 of 202), and E. histolytica and E. moshkovskii in $1.0 \%$ (2 of 202) of stool samples. The test also detected mixed infections by all the three species (E. histolytica, E. dispar and E. moshkovskii) in 7.4\% (15 of 202) of stool samples (Table 1). The result of the nested multiplex PCR as compared with microscopy and culture is also summarized in Table 1. 

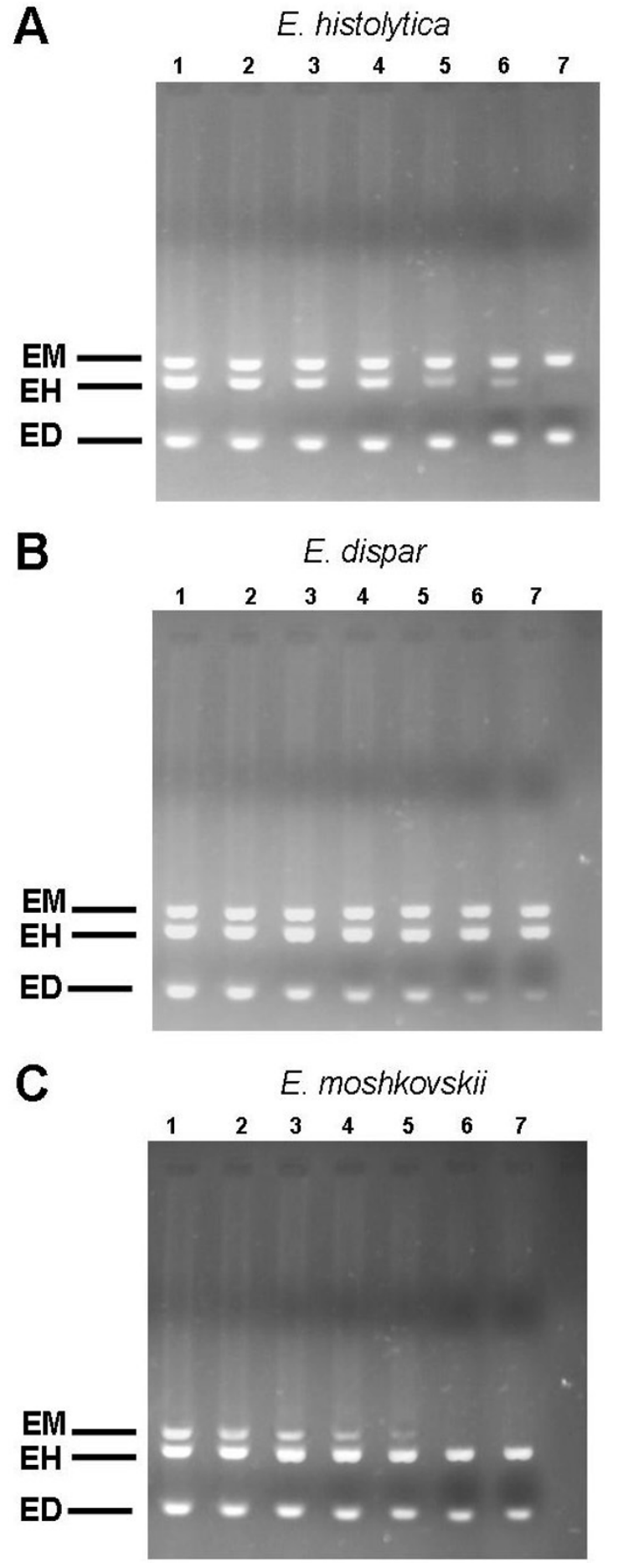

\section{Figure 2}

Detection of $E$. histolytica (A), E. dispar (B) and E. moshkovskii (C) in mixed cell lysates. To 1000 cells of $E$. dispar and E. moshkovskii (A) or E. histolytica and E. moshkovskii or (B), E. histolytica and E. dispar (C), 1000 cells (lane I), I 00 cells (lane 2 ), I 0 cell (lane 3 ), I cell (lane 4 ), 0.1 cell (lane 5 ), 0.0 I cell (lane 6) and 0.001 cell (lane 7) of the other species were added. Amplification was done by nested multiplex PCR.

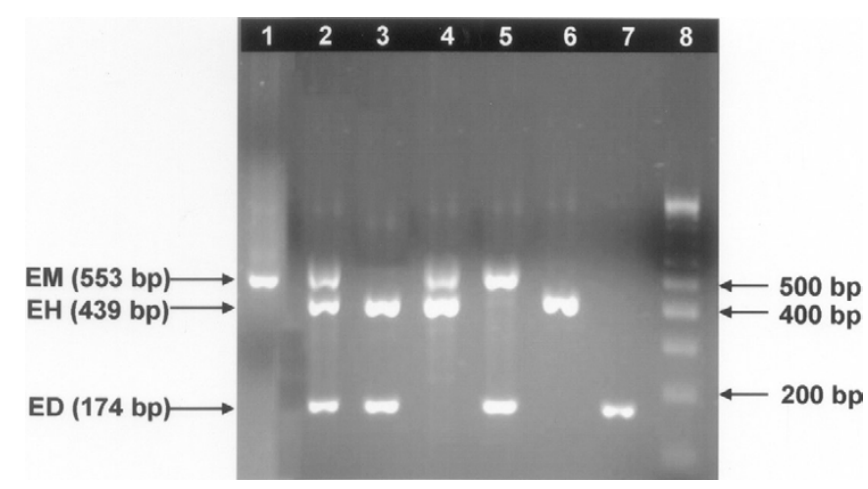

\section{Figure 3}

Differential detection of E. histolytica, E. moshkovskii and $E$. dispar by nested multiplex PCR on stool samples. The E. moshkovskii (EM), E. histolytica (EH) and E. dispar (ED) bands are 553, 439 and I 74 bp, respectively. Lane-I, E. moshkovskii (mono infection); Lane-2, E. moshkovskii, E. histolytica and $E$. dispar (mixed infection); Lane-3, E. histolytica and $E$. dispar (mixed infection); Lane-4 E. moshkovskii and E. histolytica (mixed infection); Lane-5, E. moshkovskii and E. dispar (mixed infection); Lane-6 $E$. histolytica (mono infection), Lane-7 $E$. dispar (mono infection); Lane-8, 100 bp DNA ladder (Bangalore genei, Bangalore).

PCR positivity of E. dispar, E. histolytica and E. moshkovskii among the stool samples that were positive for E. histolytica/E. dispar/E. moshkovskii by microscopy and/or culture is presented in Table 2.

\section{TechLab E. histolytica II ELISA}

The TechLab E. histolytica II ELISA test was performed to detect $E$. histolytica coproantigen in 45 randomly selected stool samples that were positive for E. histolytica/E. dispar/ E. moshkovskii complex by microscopy and/or culture.

The TechLab E. histolytica II ELISA detected coproantigen in 29 out of $45(64.4 \%)$ stool specimens positive for $E$. histolytica/E. dispar/E. moshkovskii complex by microscopy and/or culture. These 29 amoebic antigen positive stool specimens included 4 specimens positive for E. histolytica as mono-infection, 17 specimens positive for $E$. histolytica and E. dispar as mixed-infection, 1 specimen positive for E. histolytica and E. moshkovskii as mixed-infection, and 7 specimens positive for all the three species namely $E$. histolytica, E. moshkovskii and E. dispar as mixed-infection by the nested multiplex PCR (Table 3).

Comparison of results of nested multiplex PCR and TechLab E. histolytica II ELISA test performed on 45 stool specimens is summarised in the table 3 .

\section{Discussion}

To be able to detect and distinguish E. histolytica, E. dispar and E. moshkovskii in stool samples is extremely important 
Table 2: PCR positivity (\%) of E. dispar, E. moshkovskii among the stool samples that were positive for $E$. histolyticalE. dispar/E. moshkovskii by microscopy and/or culture ${ }^{a}$.

\begin{tabular}{lcc}
\hline $\begin{array}{c}\text { Type of Entamoeba } \\
\text { species }\end{array}$ & $\begin{array}{c}\text { No. of samples positive by nested } \\
\text { multiplex PCR }\end{array}$ & (\%) \\
\hline E. moshkovskii & 37 & 2.1 \\
E. dispar & 171 & 9.9 \\
E. histolytica & 70 & 4.0 \\
\hline
\end{tabular}

a Total number of stool samples collected from patients attending JIPMER hospital, Puducherry, India, with complaints of gastrointestinal discomfort $=1,720$

for accurate diagnosis of intestinal amoebiasis and for knowing the true prevalence of pathogenic E. histolytica in the community. Various DNA based molecular methods have been evaluated for accurate detection of E. histolytica, E. dispar or E. moshkovskii [2,6,9-16].

The present study, describes a new nested multiplex PCR strategy for species-specific detection and differentiation of E. histolytica, E. dispar and E. moshkovskii DNA directly in the stool samples of patients.

Recently a single round PCR to detect E. histolytica, E. dispar and E. moshkouskii in stool samples has been reported by Hamzah et al [17], the study reported that out of 27 stool samples positive for Entamoeba spp. by microscopy only 7 were successfully identified at species level by PCR, which included 1 positive for E. histolytica and 6 for E. dispar, but no amplification of E. moshkovskii was observed in a Thai population [17]. In contrast, our study has shown the presence of E. moshkouskii in the Indian population. The negative result for E. moshkovskii in Thai population may be attributed to the small sample size used in the study. A detailed comparative study between these two newly described PCR techniques may yield useful information especially in the field of molecular-based diagnosis of intestinal amoebiasis.

Nested PCR was used in the present study because it increases sensitivity [18]. Clinical specimens such as stool often contain PCR inhibitors even after purification steps. The two rounds of PCR might have assisted in compensating the effects of inhibitors present in clinical specimens. The first PCR product may be in too low concentration for detection with ethidium bromide stained gels using a UV transilluminator. The detection limit of agarose gel electrophoresis with ethidium bromide stain using an UV transilluminator is approximately $10 \mathrm{ng}$ of DNA [19]. The product of first PCR may be just enough to provide adequate templates for the synthesis of second PCR product in the nested reaction to be detected by ethidium bromide staining.

The nested multiplex PCR was negative in 12 out of 202 stool specimens that were positive for $E$. histolytica/E. dispar/E. moshkovskii complex trophozoites/cysts by microscopy and/or culture. The negative result due to inhibition of PCR in all these 12 stool samples was ruled out by spiking with standard DNA of Entamoeba followed by nested multiplex PCR amplification.

The negative PCR result in these 12 stool samples may be due to the presence of other Entamoeba species. However, we feel that this supposition needs to be proven by further development of molecular tools to confirm the presence of other Entamoeba species commonly found in humans, such as E. coli, E. hartmanni or other similar looking Entamoeba species. Till then these negative results may be imputed to the sensitivity limitation of the nested multiplex PCR technique.

Table 3: Comparison of results of nested multiplex PCR (Polymerase Chain Reaction) and TechLab E. histolytica II ELISA test performed on stool specimens.

\begin{tabular}{lccc}
\hline Nested multiplex PCR result & TechLab E. histolytica II stool specimen test result ${ }^{a}$ & Total no. of specimen \\
\cline { 2 - 3 } & Positive & Negative & $\mathbf{8}$ \\
\hline E. dispar (mono infection) & $\mathbf{0}$ & $\mathbf{2}$ & $\mathbf{8}$ \\
E. histolytica (mono infection) & $\mathbf{4}$ & $\mathbf{0}$ & $\mathbf{0}$ \\
E. moshkovkii (mono infection) & $\mathbf{0}$ & $\mathbf{2}$ & $\mathbf{2}$ \\
E. dispar + E. moshkovkii (mixed) & $\mathbf{0}$ & $\mathbf{1}$ & $\mathbf{1}$ \\
E. dispar + E. histolytica (mixed) & $\mathbf{1 7}$ & $\mathbf{0}$ & $\mathbf{1 0}$ \\
E. histolytica + E. moshkovskii (mixed) & $\mathbf{1}$ & $\mathbf{3}$ & $\mathbf{0}$ \\
E. dispar+E. histolytica+E. moshkovskii (mixed) & $\mathbf{7}$ & $\mathbf{0}$ & $\mathbf{4 5}$ \\
Negative & $\mathbf{0}$ & $\mathbf{1 6}$ &
\end{tabular}

${ }^{a} E$. histolytica II ELISA test is designed to detect only $E$. histolytica specific lectin antigen in stool specimen and therefore can confirm only the presence of E. histolytica. 
In the present study by using nested multiplex PCR it was shown that the rate of mono infection with $E$. dispar was the highest. E. dispar was demonstrated in 100 out of 202 stool samples $(49.5 \%)$ amongst patients attending JIPMER hospital. The study also shows that the rate of coinfection with $E$. histolytica and $E$. dispar was the highest $(18.8 \%)$ as compared to both, E. dispar and E. moshkovskii (8.9\%), and E. histolytica and E. moshkovskii (1.0\%). The occurrence of co-infection with E. dispar and E. histolytica in the stool specimens has been documented by several studies reported earlier $[9,10,12,20,21]$.

Nested multiplex PCR was positive for E. histolytica DNA in 6 stool specimens which were negative for coproantigen by TechLab ELISA. The possible reason for such occult infection (PCR-positive, ELISA-negative stool specimens for $E$. histolytica) may be due to degradation of lectin antigen in stool specimen due to prolonged storage (approximately $30-60$ days) at $-20^{\circ} \mathrm{C}$ prior to testing; thus resulting in a negative test for amoebic coproantigen by the ELISA.

In the present study the overall correlation between the results of nested multiplex PCR and that of TechLab E. histolytica II ELISA to detect $E$. histolytica in stool specimen was greater than $90 \%$. This agreement between these two techniques shows clearly that either of the techniques may be used alone to yield an accurate assessment of the presence of $E$. histolytica in a stool specimen, but not for the detection of either E. dispar or E. moshkovskii in stool specimens by TechLab E. histolytica II ELISA.

The inability of TechLab E. histolytica II ELISA to detect either E. dispar or E. moshkovskii in stool specimens is the noted disadvantage of the test. The nested multiplex PCR, on the other hand appears to be more useful for simultaneous detection of all the three species,E. histolytica, E. moshkovskii and E. dispar when performed directly on the stool specimens. This is the main advantage of this test, and is of importance due to the fact that there is an increasing documentation of both E. moshkovskii and E. dispar from different parts of the world [2,6,9,11-17], including from Puducherry, the southern union territory of India [10]. The coexistence of non-pathogenic E. dispar and E. moshkovskii as mixed infection or solely as monoinfection amongst the patients showed an increased possibility of faulty diagnosis when the identification of $E$. histolytica was based primarily on morphology by microscopic examination of stool. The high PCR positivity of $E$. moshkovskii among the study population supports the view that humans are a true host for this free-living amoeba [2].

The inability to distinguish E. histolytica from those of morphologically similar E. dispar or E. moshkovskii in the stool samples is the main limitation of microscopy or culture. As shown in the present study only $34.6 \%$ of 202 stool specimens positive for E. histolytica, E. dispar or E. moshkouskii complextrophozoites/cysts by either microscopy or culture were actually E. histolytica and the remaining majority of stool specimens were positive for $E$. dispar and/or E. moshkovskii. In the absence of tests such as the nested multiplex PCR or ELISA for specific detection of $E$. histolytica, the majority of suspected infections would have been wrongly diagnosed as E. histolytica infection and treated unnecessarily with anti-amoebic drugs. We therefore, recommend the use of the nested multiplex PCR for simultaneous detection and accurate identification of all the three Entamoeba species in stool specimens.

\section{Conclusion}

The present study reports a new nested multiplex PCR strategy for species specific detection and differentiation of E. histolytica, E. dispar and E. moshkovskii DNA in stool specimens. The test is highly specific, sensitive and also rapid; results of the test are available within 12 hours of receipt of stool specimens.

\section{Methods \\ Sample details}

A total of 1,755 stool samples were collected in the present study during a study period of two years from July 2004 to July 2006 . This included 1,720 stool specimens collected from patients attending JIPMER hospital, Puducherry, India, with complaints of gastrointestinal discomfort. It also included 35 stool samples, as control samples, collected from healthy persons as well as patients with other intestinal infections. The 35 control stool samples included 15 stool samples negative for common enteric pathogens from healthy persons, 6 samples positive for enteric bacteria by bacterial culture, 10 positive for Giardia intestinalis cysts and 4 for eggs of Ascaris lumbricoides. All these 35 stool samples were negative for E. histolytica/E. dispar/E. moshkovskii complex cysts and trophozoites by microscopy and culture.

Fresh unpreserved stool samples were collected in sterile capped containers for examination by microscopy and culture for E. histolytica/E. dispar/E. moshkovskii complex. Aliquots of fresh unpreserved stool samples were stored at $-20^{\circ} \mathrm{C}$ until used for PCR and ELISA tests.

\section{Microscopic examination of stool}

Both saline and iodine wet mounts of fresh unpreserved stool samples were examined microscopically for demonstrating E. histolytica/E. dispar/E. moshkovskii complex cysts and trophozoites as previously described [22]. Briefly, saline wet mounts were made by mixing approximately 2 $\mathrm{mg}$ of stool with a drop of physiological saline on a glass microscope slide and placing a cover slip over the stool 
suspension. Similarly, iodine wet mounts were prepared by adding approximately $2 \mathrm{mg}$ of stool to a drop of Lugol's iodine (diluted 1:5 with distilled water) on a glass microscope slide and placing a cover slip on the stool suspension. These wet mounts were microscopically examined initially by using a low-power $(10 \times)$ objective and then using a high-power $(40 \times)$ objective of a compound light microscope. The wet mount was read in approximately 5 min to view at least 100 fields per slide. Each stool sample was screened by at least three well trained microscopists before reporting negative results in our laboratory.

\section{Stool culture}

Stool samples were cultured for Entamoeba species in Locke-egg (LE) medium (NIH modification of Boeck and Drbohlav's medium) within $6 \mathrm{~h}$ of collection as previously described $[23,24]$.

\section{Nested multiplex- polymerase chain reaction (PCR)} Extraction of genomic Entamoeba DNA

The DNA was isolated from stool specimens by a cetyltrimethylammonium bromide (CTAB) extraction method modified from previously described method for DNA isolation from in vitro cultures of Entamoeba [25]. Briefly, 50 $\mathrm{mg}$ of stool specimen, was dispersed in $250 \mu \mathrm{l}$ of lysis buffer ( $0.25 \%$ sodium dodecyl sulfate in $0.1 \mathrm{M}$ EDTA, $\mathrm{pH}$ $8.0)$, and $100 \mu \mathrm{g} / \mathrm{ml}$ of proteinase $\mathrm{K}$ was added. The lysate was incubated at $55^{\circ} \mathrm{C}$ for 2 hours. Then $75 \mu$ of $3.5 \mathrm{M}$ $\mathrm{NaCl}$ followed by $42 \mu \mathrm{l}$ of $10 \% \mathrm{CTAB} / 0.7 \mathrm{M} \mathrm{NaCl}$ (heated to $55^{\circ} \mathrm{C}$ ) was added. After the components were mixed, the sample was incubated at $65^{\circ} \mathrm{C}$ for $30 \mathrm{~min}$. This was followed by extractions with equal volumes of chloroform and then phenol-chloroform-isoamyl alcohol, and the DNA was precipitated with ice cold ethanol. The dried DNA pellet was dissolved in sterile distilled water and passed over a DNA clean-up spin column (Bangalore Genei KT-62, Bangalore). The DNA was finally eluted from the spin column in $100 \mu$ l of Tris-EDTA (TE) buffer; $2.5 \mu \mathrm{l}$ of this DNA solution was used in the PCR reaction.

\section{Quantification of DNA in stool specimen}

Quantification of DNA in spin column purified DNA extract from stool specimens was determined by UV absorbance using a Cintra 5 double beam spectrophotometer. DNA yields were calculated on the basis of UV absorbance $\times$ dilution. The purity of the nucleic acid in the samples was estimated by the ratio of readings at $260 \mathrm{~nm}$ and $280 \mathrm{~nm}\left(\mathrm{OD}_{260} / \mathrm{OD}_{280}\right)$. The quantification of DNA was done only for representative stool specimens to know the DNA yielding capacity of the CTAB-DNA extraction method and also to estimate the purity of extracted DNA for its suitability to be used in PCR.

\section{Primer design}

The genus specific primers were designed using nucleotide sequences of 16S- like rRNA gene of E. dispar, E. histolytica and E. moshkovskii Laredo deposited in GenBank with accession number [GenBank:Z49256], [GenBank:X56991] and [GenBank:AF149906] respectively. The comparison of all the three 16S-like rRNA gene sequences of E. dispar, E. histolytica and E. moshkovskii Laredo revealed significant differences enough to design species specific primers. The primers were designed using Primer 3 on-line software [26]. The primer sequences used for nested multiplex PCR are shown in table 4 .

\section{Primer validation}

The primer sequences designed for E. moshkovskii, E. histolytica, and E. dispar were subjected to a Basic Local Alignment Search Tool (BLAST) in the genome database of all organisms [27] and were found to be specific for the study.

The amplified PCR products of all the three species in stool samples were confirmed by getting both the strands of DNA sequenced on ABI PRISM 377 sequencer (Indian Institute of Science, Bangalore, India). Briefly, the ABI PRISM 377 DNA sequencer automatically analyzes DNA molecules labeled with multiple fluorescent dyes. After samples are loaded onto the system's vertical gel, they

Table 4: Primer sequences used for nested multiplex PCR

Genus specific primers (First PCR)

Entamoeba genus
E-I 5' TAAGATGCACGAGAGCGAAA 3' (forward primer)

E-2 5' GTACAAAGGGCAGGGACGTA 3' (reverse primer)

Species specific primers (Second nested multiplex PCR)

E. histolytica species

E. moshkovskii species

E. dispar species
EH-I 5' AAGCATTGTTTCTAGATCTGAG 3' (forward primer)

EH-2 5' AAGAGGTCTAACCGAAATTAG 3' (reverse primer)

Mos-I 5' GAAACCAAGAGTTTCACAAC 3' (forward primer)

Mos-2 5' CAATATAAGGCTTGGATGAT 3' (reverse primer)

ED-I 5' TCTAATTTCGATTAGAACTCT 3' (forward primer)

ED-2 5' TCCCTACCTATTAGACATAGC 3' (reverse primer) 
undergo electrophoresis, laser detection, and computer analysis. Electrophoretic separations are viewed on-screen in real-time. Software enables this system to support sequencing and fragment analysis applications. ABI PRISM 377 DNA sequencer can generate readings up to 900 bases per sample with $98.5 \%$ accuracy. The sequencing was done using species specific primers of each species. For example, the PCR product of E. histolytica DNA was sequenced using the species specific primer EH-1/EH2, E. dispar using ED-1/ED-2 and E. moshkovskii using Mos$1 /$ Mos-2.

The PCR product from stool samples showing mixed infection by multiplex PCR were sent for sequencing which included stool samples with mixed infection containing all the three species (E. histolytica $+E$. dispar $+E$. moshkovskii). Each species DNA was amplified separately with respective species specific primers before sending for sequencing. All sequences were analyzed for homology by using the nucleotide-nucleotide "BLAST" search feature [27]. The identities between the sequencing result of PCR product of E. dispar, E. histolytica and E. moshkovskii with the sequence deposited in GenBank, with accession number [GenBank:Z49256], [GenBank:X56991] and [GenBank:AF149906] respectively, were analyzed by using the "Align two sequences (bl2seq)" feature [27].

\section{Standard strains}

Three standard strains used in this study were E. histolytica HM-1: IMSS, E. dispar SAW760, and E. moshkovskii Laredo. These were used as a positive control in the present study. The lyophilized DNA of these strains was generously gifted by Dr. C. Graham Clark from London School of Hygiene \& Tropical Medicine, London, UK.

\section{Nested multiplex PCR protocol}

For a reaction volume of $25 \mu \mathrm{l}$, comprising $2.5 \mu \mathrm{l}$ of $10 \mathrm{X}$ PCR buffer (Biogene), $1.5 \mu \mathrm{l}$ of $25 \mathrm{mM} \mathrm{MgCl}_{2}$ (Bangalore genei), $1.4 \mu \mathrm{l}$ of deoxynucleoside triphosphate mix (5 $\mathrm{mM}$ each dNTP, ABgene), $0.3 \mu \mathrm{l}$ ( $5 \mathrm{IU} / \mu \mathrm{l}$ ) of Taq polymerase (Biogene), $0.3 \mu \mathrm{M}$ of each primer (IDT) and $2.5 \mu \mathrm{l}$ of template DNA was added in genus specific and species specific PCR. The PCR tubes were finally placed in an Eppendorf Thermal cycler [Master cycler gradient].

\section{The conditions for genus specific PCR were as follows}

The PCR mix was subjected to an initial denaturation at $96^{\circ} \mathrm{C}$ for 2 minutes, followed by 30 cycles - each consisting of $92^{\circ} \mathrm{C}$ for 60 seconds (Denaturation), $56^{\circ} \mathrm{C}$ for 60 seconds (Annealing), and $72^{\circ} \mathrm{C}$ for 90 seconds (Extension). Finally one cycle of extension at $72^{\circ} \mathrm{C}$ for seven minutes was performed. In the species specific nested multiplex PCR (which had multiple primer sets in the same tube), only the annealing temperature was changed to $48^{\circ} \mathrm{C}$, leaving the other parameters of the amplification cycles unchanged.

Three micro litres of the amplification products were separated by electrophoresis through $1.8 \%$ agarose gel (Agarose Low EEO, Bangalore genie products, Bangalore, India) in $0.5 \times$ Tris-borate-EDTA at $120 \mathrm{~V}$ for $45 \mathrm{~min}$ and were visualized by ethidium bromide staining under UV light for bands of DNA of appropriate sizes (Figure 3). Positive and negative control reactions were included with each batch of samples analyzed by nested multiplex PCR.

\section{Assessment of competition for non-target DNA}

To assess the competition of other non-target DNA present in stool samples with target DNA, the nested multiplex PCR was checked with reference DNA (DNA from standard strain of E. histolytica, E. dispar and E. moshkovskii) spiked with DNA from negative control stool samples (negative by microscopy and culture) followed by nested multiplex PCR amplification.

\section{Estimation of minimum number of Entamoeba cells detectable by nested multiplex PCR}

To determine the minimum number of Entamoeba cells detectable by nested multiplex PCR, all the three species were studied by Locke-egg (LE) medium (NIH modification of Boeck and Drbohlav's medium) cultures and the amoebae were counted using a standard haemocytometer. A cell pellet containing $10^{6}$ cells was preferred for determining the detection limit of nested multiplex PCR for each Entamoeba species. The cell pellet containing $10^{6}$ cells of E. histolytica, E. dispar and E. moshkovskii was diluted ten folds in Phosphate buffer saline (PBS) to obtain different concentrations of cells, such as $10^{5}, 10^{4}, 10^{3}, 10^{2}$ and 10 cells. The different quantities of cells ranging from $10^{6}$ to 10 cells were added to 0.05 gm of faeces (negative control stool samples) followed by DNA extraction and PCR as per the aforementioned protocol.

Estimation of nested multiplex PCR to detect mixed infections with $\mathrm{E}$. histolytica, E. dispar and E. moshkovskii species

A variable number of lysed E. histolytica cells (ranging from 1000 cells to 0.001 cell) were mixed with a constant number (that is 1000 cells) of each of the lysed E. dispar and E. moshkovskii cells; a variable number of lysed E. dispar cells (ranging from 1000 cells to 0.001 cell) were mixed with a constant number (that is 1000 cells) of each of the lysed E. histolytica and E. moshkovskii cells; a variable number of lysed E. moshkovskii cells (ranging from 1000 cells to 0.001 cell) were mixed with a constant number (that is 1000 cells) of each of the lysed E. histolytica and E. dispar cells, followed by DNA extraction and PCR as per the aforementioned protocol. 
Cross checking the results of nested multiplex PCR

Some of the representative stool samples showing mixed infection by nested multiplex PCR were selected randomly and subjected to species specific individual nested PCR, with species specific primers for each species, in separate PCR tubes.

\section{TechLab E. histolytica II ELISA test}

The TechLab E. histolytica II ELISA test was performed to detect E. histolytica coproantigen in 45 randomly selected stool samples, positive for E. histolytica/E. dispar/E. moshkovskii complex, by microscopy and/or culture, and also positive for E. histolytica, E. dispar and E. moshkovskii DNA by nested multiplex PCR. The TechLab E. histolytica II ELISA test was performed as per the instructions of the manufacturer. The kit was generously given for the purpose of research by TechLab, Inc. (Blacksburg, Va.).

\section{Authors' contributions}

KK carried out the experimental works, and drafted the manuscript. SCP supervised and coordinated the study, and helped in the completion of the manuscript.

\section{Acknowledgements}

We sincerely thank Dr. C. Graham Clark from London School of Hygiene \& Tropical Medicine for providing us with lyophilized DNA of standard cultures of E. histolytica HM-I: IMSS, E. dispar SAW760, and E. moshkovskii Laredo. We are also grateful to TechLab, Inc. (Blacksburg, Va. USA) for providing the TechLab E. histolytica II ELISA test kit free of cost for the purpose of research.

\section{References}

I. World Health Organization: Amoebiasis. WHO Weekly Epidemiol Rec 1997, 72:97-100.

2. Ali IK, Hossain MB, Roy S, Ayeh-Kumi PF, Petri WA Jr, Haque R, Calrk CG: Entamoeba moshkovskii infections in children, Bangladesh. Emerg Infect Dis 2003, 9:580-584.

3. Gonzalez-Ruiz A, Haque R, Aguirre A, Castanon G, Hall A, Guhl F, Ruiz-Palacios G, Miles MA, Warhurst DC: Value of microscopy in the diagnosis of dysentery associated with invasive Entamoeba histolytica. J Clin Pathol 1994, 47:236-239.

4. Krogstad DJ, Spencer HC Jr, Healy GR, Gleason NN, Sexton DJ, Herron CA: Amebiasis: epidemiologic studies in the United States, 197I-1974. Ann Intern Med 1978, 88:89-97.

5. Haque R, Neville LM, Hahn P, Petri WA Jr: Rapid diagnosis of Entamoeba infection by using Entamoeba and Entamoeba histolytica stool antigen detection kits. I Clin Microbiol 1995, 33:2558-256I.

6. Huston CD, Haque R, Petri WA Jr: Molecular-based diagnosis of Entamoeba histolytica infection. Expert Rev Mol Med 1999, 22:I-II.

7. Pillai DR, Kain KC: Immunochromatographic strip-based detection of Entamoeba histolytica-E. dispar and Giardia lamblia coproantigen. J Clin Microbiol 1999, 37:3017-3019.

8. Garcia LS, Shimizu RY, Bernard CN: Detection of Giardia lamblia, Entamoeba histolytica/Entamoeba dispar, and Cryptosporidium parvum antigens in human fecal specimens using the Triage parasite panel enzyme immunoassay. J Clin Microbiol 2000, 38:3337-3340

9. Haque R, Ali IKM, Akther S, Petri WA Jr: Comparison of PCR, isoenzyme analysis, and antigen detection for diagnosis of Entamoeba histolytica infection. J Clin Microbiol 1998, 36:449-452.

10. Parija SC, Khairnar K: Entamoeba moshkovskii and Entamoeba dispar-associated Infections in Pondicherry, India. J Health Popul Nutr 2005, 23:292-295.
II. Tanyuksel M, Petri WA Jr: Laboratory diagnosis of amebiasis. Clin Microbiol Rev 2003, 16:713-729.

12. Nunez YO, Fernandez MA, Torres-Nunez D, Silva JA, Montano I, Maestre JL, Fonte L: Multiplex polymerase chain reaction amplification and differentiation of Entamoeba histolytica and Entamoeba dispar DNA from stool samples. Am J Trop Med Hyg 200I, 64:293-297.

13. Furrows SJ, Moody AH, Chiodini PL: Comparison of PCR and antigen detection methods for diagnosis of Entamoeba histolytica infection. J Clin Pathol 2004, 57: I264-I 266.

14. Gonin P, Trudel L: Detection and differentiation of Entamoeba histolytica and Entamoeba dispar isolates in clinical samples by PCR and enzyme-linked immunosorbent assay. J Clin Microbiol 2003, 41:237-24I.

15. Sharma AK, Chibbar S, Bansal G, Kaur U, Vohra H: Evaluation of newer diagnostic methods for the detection and differentiation of Entamoeba histolytica in an endemic area. Trans $R$ Soc Trop Med Hyg 2003, 97:396-397.

16. Roy S, Kabir M, Mondal D, Ali IK, Petri WA Jr, Haque R: Real-timePCR assay for diagnosis of Entamoeba histolytica infection. J Clin Microbiol 2005, 43:2168-2I 72.

17. Hamzah Z, Petmitr S, Mungthin M, Leelayoova S, Chavalitshewinkoon-Petmitr P: Differential detection of Entamoeba histolytica, Entamoeba dispar, and Entamoeba moshkovskii by a singleround PCR assay. J Clin Microbiol 2006, 44:3196-200.

18. Messmer TO, Skelton SK, Moroney JF, Daudharty H, Fields BS: Application of a Nested, Multiplex PCR to Psittacosis Outbreaks. J Clin Microbiol 1997, 35:2043-2046.

19. Sambrook J, Russell DW: Gel Electrophoresis of DNA and Pulsed-field Agarose Gel Electrophoresis. In Molecular Cloning, A Laboratory Manual 3rd edition. New York, USA, Cold Spring Harbor Laboratory Press; 2000:5.14-5. 15.

20. Newton-Sanchez OA, Sturm-Ramirez K, Romero-Zamora JL, SantosPreciado JI, Samuelson J: High rate of occult infection with Entamoeba histolytica among non-dysenteric Mexican children. Arch Med Res 1997, 28:S3II-S3I3.

21. Romero JL, Descoteaux S, Reed S, Orozco E, Santos J, Samuelson J: Use of polymerase chain reaction and nonradioactive DNA probes to diagnose Entamoeba histolytica in clinical samples. Arch Med Res 1992, 23:277-279.

22. Parija SC, Prabhakar PK: Evaluation of lacto-phenol cotton blue for wet mount preparation of feces. J Clin Microbiol 1995, 33:1019-1021.

23. Parija SC, Rao RS: Stool culture as a diagnostic aid in the detection of Entamoeba histolytica in the faecal specimens. Indian J Pathol Microbiol 1995, 38:359-363.

24. Clark CG, Diamond LS: Methods for cultivation of luminal parasitic protists of clinical importance. Clin Microbiol Rev 2002, 15:329-4I.

25. Clark CG, Diamond LS: The Laredo strain and other Entamoeba histolytica-like amoebae are Entamoeba moshkovskii. Mol Biochem Parasitol 199I, 46: I I-18.

26. Primer3 Input [http://frodo.wi.mit.edu/]

27. BLAST: Basic Local Alignment and Search Tool [http:// www.ncbi.nlm.nih.gov/blast/]

Publish with BioMed Central and every scientist can read your work free of charge

"BioMed Central will be the most significant development for disseminating the results of biomedical research in our lifetime. "

Sir Paul Nurse, Cancer Research UK

Your research papers will be:

- available free of charge to the entire biomedical community

- peer reviewed and published immediately upon acceptance

- cited in PubMed and archived on PubMed Central

- yours - you keep the copyright
BioMedcentral 